\title{
Research on the New Changes and Countermeasures of Human Resources Management under Big Data and Artificial Intelligence
}

\author{
Fengxiang Jiang, Sisi Wang \\ Xi'an Peihua University, Xi’an Shaanxi 710125
}

Keywords: big data; AI; Human resources management; new changes; countermeasures

\begin{abstract}
With the development of Internet technology and the arrival of big data and AI era, the human resource management of enterprises is deeply influenced. Big data can be used for management for a large number of human resource information enterprises, to improve the efficiency and quality of enterprise human resource management, thus ensure that the enterprise human resource management is in the normal operation state, and then save more costs for the enterprise. The enterprise's human resource management needs to change its idea, keep pace with the times, make full use of big data, make full use of the intelligent function of artificial intelligence, construct a brand-new human resource management mode, and create a scientific and effective management system. Big data is applied to the human resource management of the enterprise to realize the humanization and digitization of the enterprise management and to contribute to the sustainable development of the enterprise.
\end{abstract}

\section{Introduction}

With the development of science and technology, the human society has entered the era of big data and AI technology has been developed rapidly, which is changing the situation of the new era. The AI technology with Internet gene and big data closely combine, will reconstruct business form. The competition between people will be the competition of knowledge under the technology of big data and AI, which will bring new changes to the concept and mode of human resource management, the traditional human resource management cannot adapt to the changes of the new era, and enterprises should adapt to the requirements of the development of the era, to actively adapt to the new changes and trends of the times, set up the concept of "intelligent human resource management", reconstruct the mode of human resources management, attach importance to the sharing and outsourcing of human resources services, and construct the network platform of human resources management, to realize the intelligent management of human resources, to continuously reduce the cost of enterprises, to improve the management level and economic benefits of enterprises.

\section{Big data and AI}

Big data means huge amount of information, refers to the massive, high growth rate and diversified information assets that require a new processing model to have greater decision-making power, insight and process optimization capabilities. Big data has 5 ' $\mathrm{V}$ features: volume, velocity, variety, value, veracity.

AI is Artificial Intelligence, short for AI. Artificial intelligence is the simulation of the information process of human consciousness and thinking. Artificial intelligence is not human intelligence, but the ability to think like a person, may also exceed human intelligence.

\section{Traditional human resource management}

Human resource management means that the relevant human resources within and outside the organization can be effectively utilized through the management of recruitment, selection, training, compensation, and so on under the guidance of economics and humanism, so as to meet the needs 
of the current and future development of the organization, including a series of activities that ensure the maximization of organizational goals and the development of members. Human resource management can stimulate the potential of employees, fully mobilize the initiative, enthusiasm and creativity of employees, create more value for enterprises, and enhance the economic benefits of enterprises. There are many human resource management activities, including the formulation of enterprise human resources strategy and planning, employee recruitment and configuration, employee training and development, performance management, compensation management, employee mobility management, employee labor relations management, staff safety and health management, human resource management involves a variety of work content. It is necessary for enterprises to adopt to modern management methods, make full use of modern technology, and innovate human resources management model in the new era.

\section{New changes of human resource management under big data and AI}

The form and value of human resource management have changed greatly under big data and AI, human resource management tends to be digitalized, the function of human resource management is more intelligent, and enterprise management pays attention to sharing and cooperation. Human resources management work tends to more intelligent, digital, platform, refined.

\subsection{Enhanced refinement of human resources management}

The timeliness of human resources information is stronger in big data era. Big data will provide more comprehensive, dynamic matching and timely updating information for human resource management to help human resource management subjects to make decisions, to realize the fine development. AI technology changes human resources management greatly, which will improve the quality requirements of human resources, and the development of human resources is more difficult.

\subsection{Human resources management needs reconfiguration}

The quality of human resources turned to the "three-dimensional ability of lifelong learning" in the era of big data and AI, the competition between people presented the knowledge and the platform of human resources management. Human resources management departments need to keep pace with the new era need to speed up the innovation of ideas, reconstruction of the management framework and so on. In the era of big data and AI, the speed of knowledge change is quickening, the competition between people is more intense, the competition between people is becoming knowledge-based, and the human resources of enterprises only establish the concept of lifelong learning. Only by maintaining the habit of improving one's own knowledge and ability can the quality of human resources meet the needs of society.

The future enterprise organizations need to establish learning organizations, attach importance to the construction of wisdom and culture, establish convenient learning platform, provide more learning resources, and meet the needs of employees in the new era. With the development of big data and AI technology, the enterprises should fully embrace the big data and AI, and develop technology platform, which can be structured and tagged through automatic data collection. Atomic processing, make the service more accurate, human resources management can be through the network platform to achieve anytime and anywhere contact and management, the communication between employees is more convenient, to improve human resources solutions to save data input time, helps employees free up more time to serve the company.

To sum up, big data and AI provide human resource individuals with more growth and three dimensions for the reconstruction of human resource quality. the individual of human resource hopes to realize the cooperation and growth of cross-organization, and to unlock his own human resource ability in all directions in the new era. When the organization is more flexible and the human resource is more three-dimensional, the traditional labor relationship based on employment relationship will be changed, and the "service relationship based on platform" will become the 
mainstream mode of human resources cooperation in the future. The "pan-platform labor relations" will reform the foundation and structure of human resource management and reconstruct the content and form of human resource management.

\subsection{Contextualization of human resources management programmes}

The enterprise uses the platform to realize the wisdom operation and the wisdom innovation step by step under big data and AI. Artificial intelligence technology has changed the business management scene. Enterprises establish human resources big data platform, integrate voice, image, biological identification technology, improve understanding of work intention, visual development, build intelligent application front end, enrich intelligent customer service, intelligent portal, intelligent group collaboration and other business scenarios, therefore, enterprises can construct an open platform with AI capability, and the enterprise can set up a scenario based on scenario.

\subsection{Decentralization of human resources management under big data and AI}

To promote the transformation and innovation of human resources management operation mode, human resources sharing service center has become a new human resources management model for large enterprise groups, large enterprises improve the operation efficiency of human resources and better service business unit through the establishment of human resource sharing service center. Human resources management decentralization, altruistic creation, career sharing, employees can be really motivated. For example, Haier offers a technology platform called the Traveler platform, which encourages employees to become entrepreneurs and make free use of technological innovation; Haier Human Resources Department integrated the development of the creation bar, Haier official recruitment platform, Haier official talent attraction platform.

\section{New countermeasure of human resource management under big data and AI}

The human resource management of the enterprise has the conditions to realize the informationization and the analysis of big data under big data and AI, using the information platform and system to effectively promote the optimization of the human resources allocation within the enterprise, to continuously improve the innovation ability of human resources, stimulate the initiative, enthusiasm and creativity of human resources, and improve the self-efficacy of employees.

\subsection{The effective planning of human resources using data}

Enterprises need to fully tap and utilize employee management data to enhance enterprise value and employee capacity. Enterprises need to make full use of big data thinking to forecast the supply and demand of human resources, apply the results of forecast analysis to the whole process of personnel recruitment and selection, and analyze the quality of human resources by the use of big data, to construct the model of human resource quality and ability, and optimize the human resource of enterprise continuously, carry on the human resource planning effectively, so as to make the enterprise carry on more effective employee management.

\subsection{Establishment of human resources management information system}

Enterprises should have big data thinking, make full use of big data, set up human resources management information system, be able to collect, process, store and issue human resources management information actively and in real time. Human Resource Management Information system (HRMS) includes basic information of employee's education, degree, title, job change, and other details. Human resource management information system can provide decision, coordination, control, analysis and visualization support for the implementation of human resource management activities in an enterprise, which can quickly retrieve and analyze the human resources information, in order to achieve the fine management of human resources information. 


\subsection{Continuous improvement of Human Resources Service system}

Technology promotes continuous innovation in enterprises in the era of big data and AI. Enterprises need to change the traditional mode of controlling their employees and continuously improve the human resources service system, to strengthen the flexible management of incentive type, let the staff participate in the enterprise management, realize the democratic management of the enterprise, stimulate the employee's initiative dedication and creativity, and create more benefit for the enterprise organization. For example, the human resources service system can track the status of human resources services, complete self-help information query of human resources information, and employers can access information such as compensation through the client side,, benefits and so on through the Internet at anytime and anywhere. They can clearly understand the progress and status of human resources services, so that customers can achieve a high degree of transparency management.

\subsection{Human resources service outsourcing}

The trend of decentralization of human resources management is obvious due to big data and AI, and it is inevitable that large enterprises establish human resource sharing service centers; small and medium-sized enterprises, small and micro enterprises, new enterprises, concentrate its efforts in the professional field and realize the maximum operating efficiency in order to reduce the cost of human resources, the branch office entrusts all or part of the work of the non-core part of the human resources affairs with the management of the professional organization of human resources service. That is, to outsource human resources management services, such as outsourcing employees' social security provident fund in other places, to solve various employee insurance problems; outsourcing employee training can enable training and development activities to be managed at a lower cost and better cost-effectiveness and clearer accountability.

\section{Conclusion}

In short, the rapid development of the Internet has made the era of big data information come. The era puts forward higher requirements for enterprises, and the ability to grasp and process data needs to be strengthened urgently. The transformation and innovation of intangible assets can not only provide enterprises with a broader space for development, but also bring immeasurable value to the social economy. Enterprises need to make full use of the large data and AI technology to realize effective human resource management and realize the "more wisdom" of human resource management under the large data and AI. Big data and AI technology are transformed into human resource management tools and methods, integrated into human resource management practices to tap, attract, recruit, cultivate and develop human resources, achieve enterprise wisdom management and wisdom innovation, and ultimately achieve the enterprise strategic development goals.

\section{References}

[1] Kun Zhou. Analysis of Enterprise Human Resource Management Reform in Big Data Era [J]. Mall Modernization, 2017 (8): 166-167.

[2] Hongwei Li. Analysis of the change of Enterprise Human Resource Management in Big Data Era [J]. Human Resources Management, 2017 (1): 9-10.

[3] Mengqiong Liu. Relevant Analysis of Human Resource Management Reform in Big Data Era [J]. Management and Technology of Small and Medium-sized Enterprises, 2017 (30): 23-24.

[4] Liu Chenchen. Reflections on the Reform of Enterprise Human Resource Management in big data era [J]. Development of Human Resources, 2016 (8): 143-143.

[5] Yun He, Xing An, Jing Xue. Reflections on the Reform of Enterprise's Human Resource Management in Big Data Era [J]. Economic Research Reference, 2014 (63): 26-32. 
[6] Yi Wang. Reflections on the Reform of Enterprise's Human Resource Management in Big Data Era [J]. Economic Research, 2017 (26): 73-74. 